\title{
Higher Cortisol Levels Following Exposure to Traumatic Reminders in Abuse-Related PTSD
}

\author{
Bernet M Elzinga*,', Christian G Schmahl2 ${ }^{2}$, Eric Vermetten ${ }^{3}$, Richard van Dyck ${ }^{4}$ and J Douglas Bremner ${ }^{5,6,7}$ \\ 'Section of Clinical and Health Psychology, Leiden University, The Netherlands; ${ }^{2}$ Department of Psychiatry and Psychotherapy, University of \\ Freiburg Medical School, Germany; ${ }^{3}$ Department of Psychiatry, University Medical Center, Central Military Hospital, The Netherlands; \\ ${ }^{4}$ Department of Psychiatry, Vrije Universiteit, Amsterdam, The Netherlands; ${ }^{5}$ Departments of Psychiatry and Behavioral Sciences and Radiology, \\ Center for Positron Emission Tomography, Emory University School of Medicine, Atlanta, GA, USA; ${ }^{6}$ PET Center/Nuclear Medicine, Emory \\ University Hospital, Atlanta, GA, USA; ${ }^{7}$ Atlanta VAMC, Decatur, GA, USA
}

\begin{abstract}
Animal studies have found that prior stressful events can result in increased reactivity in the HPA-axis. However, baseline function of the HPA-axis has typically been normal or decreased in post-traumatic stress disorder (PTSD). The first purpose of this study was to assess cortisol responsivity to traumatic reminders in women with PTSD related to childhood abuse. The second aim was to assess the relationship between stress-induced cortisol levels and neutral and emotional memory. Salivary cortisol levels were measured before, during and after exposure to personalized trauma scripts in abused women with $(N=12)$ and without current PTSD (N=12). Memory for neutral and emotional material was assessed immediately after trauma scripts exposure and 3 days later. PTSD patients had I22\% higher cortisol levels during script exposure, 69\% higher cortisol levels during recovery, and $60 \%$ higher levels in the period leading up to the script exposure compared to controls. PTSD symptoms were highly predictive of cortisol levels during trauma script exposure $(r=0.70)$, but not during periods of rest. Both in PTSD patients and controls, memory consolidation after the trauma scripts was impaired relative to baseline $(P<0.00 \mathrm{I})$, with no differences between the two groups on memory performance. There was no association between memory performance and cortisol levels. These results are consistent with higher cortisol levels following exposure to traumatic stressors in PTSD.
\end{abstract}

Neuropsychopharmacology (2003) 28, I656-1665, advance online publication, 02 July 2003; doi: I 0. I038/sj.npp. 1300226

Keywords: cortisol; post-traumatic stress disorder; trauma; memory; neurobiology; childhood abuse

\section{INTRODUCTION}

Childhood sexual or physical abuse is associated with increased rates of a variety of psychiatric disorders, including post-traumatic stress disorder (PTSD), depression, alcohol and substance abuse, dissociative disorders, and borderline personality disorder (McCauley et al, 1997; Beitchman et al, 1992; Brown and Anderson, 1991; Draijer and Langeland, 1999). A recent survey in the US reported that childhood sexual abuse is the most common cause of PTSD in women, currently affecting $10 \%$ of all women (Kessler et al, 1995). There is a growing body of evidence in animals demonstrating that early adverse events, such as maternal deprivation, may have a lasting impact on the

Location of work: Yale Psychiatric Research, Yale University School of Medicine, New Haven, CT, USA

* Correspondence: Dr BM Elzinga, Section of Clinical and Health Psychology, Leiden University, PO Box 9555, 2300 RB Leiden, The Netherlands, Tel: + 31 7I 5273745, Fax: + 31 7I 5274678,

E-mail: elzinga@fsw.leidenuniv.nl

Received 17 May 2002; revised 08 May 2003; accepted 09 May 2003 Online publication: 16 May 2003 at http://www.acnp.org/citations/ Npp051602190/default.pdf neurobiology of the stress response, involving chronic increases in plasma glucocorticoid levels and a potentiation of glucocorticoid responsiveness to subsequent stressors (Sapolsky, 1997; Plotsky and Meany, 1993; Anisman et al, 1998). In humans, trauma early in life appears to increase the risk of developing PTSD in adulthood in response to other traumas, suggesting that early trauma reduces the capacity to cope with subsequent stressful events (Bremner et al, 1993). In spite of the high prevalence of childhood abuse and PTSD, little is known about the long-term effects of abuse on the regulation of stress.

Two biological stress systems, that is, the locus coeruleus/ noradrenergic system and the hypothalamic-pituitaryadrenal (HPA) axis are likely to mediate the association between early life stress and PTSD. Long-term alterations in these stress systems, both at baseline ('tonic') and with exposure to trauma cues ('phasic'), have been documented in PTSD subjects (Bremner et al, 1999). Exposure of patients with PTSD to scripts of the individual's traumatic experiences have resulted in an increase in sympathetic responses (eg heart rate, systolic and diastolic blood pressure, skin conductance, and (nor)epinephrine) in comparison to traumatized persons without PTSD (Pitman 
et al, 1990, 1987; Liberzon et al, 1999; Orr et al, 1993; Shalev et al, 1993).

Unlike the increased sensitivity of the locus coeruleus/ noradrenergic system, baseline and challenge studies show that the HPA-axis functions in a more complicated manner. Shortly after a traumatic event (ie the 'phasic' responses), cortisol secretion is generally enhanced, as was found in soldiers being shelled (Howard et al, 1955), and in women shortly after being raped (Resnick et al, 1995; Yehuda et al, 1998). Paradoxically, basal 24-h cortisol excretion has been reported to be lower in patients with PTSD compared to controls (Mason et al, 1986; Yehuda et al, 1990, 1995b, 1996). This may be due to enhanced adrenocortical sensitivity to feedback regulation, given reports of enhanced dexamethasone suppressibility in PTSD (Yehuda et al, 1993; Stein et al, 1997) or decreased responsiveness of the adrenal cortex (Kanter et al, 2001). Other studies have reported increased cortisol in 24-h urine volumes both in combat veterans with PTSD (Pitman and Orr, 1990), in women with PTSD secondary to childhood sexual abuse (Lemieux and Coe, 1995), and in maltreated children with PTSD (De Bellis et al, 1999). In line with these latter studies, elevated levels of CRF in the cerebrospinal fluid (CSF) have been found in combat-related PTSD (Bremner et al, 1997). In sum, studies examining baseline HPA-axis function in patients with PTSD have been inconsistent, with evidence both for hypoand hypersecretion of cortisol.

As PTSD patients specifically suffer from exaggerated stress responses to trauma cues, it is particularly relevant to evaluate the reactivity of the HPA-axis to traumatic reminders. So far, studies have largely focused on baseline differences between PTSD patients and controls. One study of adult women with depression and early abuse found increased cortisol and ACTH responses to a stressful cognitive challenge (Heim et al, 2000). Recently, in a study on neuroendocrine responses to white noise and combat sounds, veterans with PTSD showed enhanced cortisol levels compared to veteran controls without PTSD and nonveteran controls (Liberzon et al, 1999). However, the timeframe of the cortisol assessment (only once before and once immediately after exposure) was inappropriate to distinguish baseline levels and cortisol reactivity to stress. Thus, it remained unclear whether elevations reflected enhanced chronic activation or anticipatory anxiety to the combat sounds and white noise. To our knowledge, no other studies have been published that directly assessed responsivity of the HPA-axis in relation to traumatic stimuli.

Recent findings shave shown that the HPA-axis plays an important role in memory functioning by its effects on the hippocampus (Bremner, 1999; Elzinga and Bremner, 2002; McEwen, 2000; McGaugh, 2000; Sapolsky, 1996), a brain structure involved in learning and memory (Squire and Zola-Morgan, 1991). Studies in animals show that high levels of GCs may have a long-term inhibitory effect on memory function with GC-mediated hippocampal toxicity and memory dysfunction with stress (McEwen et al, 1992; Sapolsky, 1996; Arbel et al, 1994; Conrad et al, 1996; Luine et al, 1994; Ohl et al, 2000). Studies in humans have also found declarative memory impairments in healthy subjects after administration of exogenous glucocorticoids (Keenan et al, 1995; Wolkowitz et al, 1990; Newcomer et al, 1994,
1999; Lupien et al, 1997, 1999) and with exposure to real-life stressors (Kirschbaum et al, 1996). In our lab, we found that a psychosocial laboratory stressor specifically impaired consolidation of information (Elzinga et al, submitted).

There are indications that PTSD patients are characterized by increased sensitivity of central GC receptors in the hippocampus (Yehuda et al, 1995a). If so, exposure to stress in patients with PTSD might result in greater impairments of declarative memory compared to control subjects. This might explain why patients with PTSD report a variety of memory disturbances, including deficits in new learning, fragmentation of (trauma-related) autobiographical memories, and trauma-related amnesia (for a review, see Elzinga and Bremner, 2002; Golier and Yehuda, 1998). So far, no study has directly assessed the relationship between stressinduced cortisol elevations and neutral and emotional memory functioning in PTSD.

The purpose of the present study was to assess cortisol levels following exposure to personalized trauma scripts in women with current PTSD related to childhood abuse and women with a history of abuse without current PTSD. We hypothesized higher cortisol levels following exposure to trauma scripts in PTSD patients relative to controls. To investigate the relationship between cortisol levels during encoding and memory performance, neutral and emotional words and paragraphs were presented immediately after exposure to the trauma scripts to assess stress-related memory functioning and 3 days later to assess delayed recall of the information and baseline memory functioning.

\section{SUBJECTS AND METHODS}

\section{Subjects}

A total of 24 women with a history of severe sexual and/or physical abuse participated in this study. Subjects included women with $(N=12)$ and without $(N=12)$ current PTSD related to childhood abuse (for subject characteristics, see Table 1). All subjects had lifetime PTSD. Subjects were recruited by advertisements in newspapers and flyers, and were paid for participation in the study. They were free of clinically significant medical or neurological illnesses. Subjects were excluded if they presented with a history of current alcohol or substance abuse or dependence in the past 6 months, organic mental disorders, or comorbid psychotic disorders based on the Structured Clinical Interview for DSM-IV axis I disorders (SCID-I; First et al, 1995). Of the 12 control subjects, five were taking psychotropic medication during participation in the study (two subjects were using $20 \mathrm{mg}$ paroxetine, one was using $40 \mathrm{mg}$ nefazadone, one was using $250 \mathrm{mg}$ sertraline, and one was using $300 \mathrm{mg}$ bupropion), and four of 12 PTSD subjects (two were using $10 \mathrm{mg}$ paroxetine, one was using $20 \mathrm{mg}$ paroxetine, and one was using $40 \mathrm{mg}$ citalopram). Subjects using benzodiazepines were excluded from the study because of the known negative effects on memory functioning. After an introduction to the study, all subjects gave written informed consent for their participation in a protocol approved by the Human Investigation Committee of Yale University. The procedure was in accord with the Helsinki Declaration of 1975. 
Table I Subject Characteristics

\begin{tabular}{|c|c|c|c|}
\hline & $\begin{array}{c}\text { PTSD }(n=12) \\
\text { Mean } \pm \text { SD }\end{array}$ & $\begin{array}{c}\text { Controls }(n=12) \\
\text { Mean } \pm \text { SD }\end{array}$ & $P$-value two-tailed \\
\hline Mean age (years) & $35.67 \pm 9.94$ & $38.75 \pm 10.47$ & NS \\
\hline Height & $65.08 \pm 2.50$ & $64.50 \pm 2.15$ & NS \\
\hline Weight & $150.58 \pm 43.15$ & $183.83 \pm 58.63$ & NS \\
\hline \multicolumn{4}{|l|}{ Ethnicity } \\
\hline White & II & 7 & \\
\hline Black & 0 & 3 & \\
\hline Hispanic & । & 2 & \\
\hline Education (years) & $14.36 \pm 2.69$ & $|6.08 \pm 2.7|$ & NS \\
\hline \multicolumn{4}{|l|}{ Comorbid diagnoses } \\
\hline MDD & 3 & 0 & \\
\hline Other anxiety disorders & 4 (2 Soc Ph, GAD, PD) & 2 (PDwA, Social Ph) & \\
\hline Early trauma inventory & $76.50 \pm 23.45$ & $74.89 \pm 44.25$ & NS \\
\hline General trauma & $25.00 \pm 11.62$ & $28.10 \pm 17.23$ & NS \\
\hline Physical abuse & $11.92 \pm 8.81$ & $14.00 \pm 10.79$ & NS \\
\hline Emotional abuse & $23.58 \pm 11.20$ & $14.44 \pm 14.14$ & NS \\
\hline Sexual abuse & $16.00 \pm 10.53$ & $15.70 \pm 10.31$ & NS \\
\hline CAPS total & $79.00 \pm 11.78$ & $19.08 \pm 12.24$ & 0.0001 \\
\hline CAPS-B (re-experiencing) & $15.83 \pm 5.22$ & $3.92 \pm 4.08$ & 0.0001 \\
\hline CAPS-C (avoidance) & $32.83 \pm 7.90$ & $6.83 \pm 6.83$ & 0.0001 \\
\hline CAPS-D (arousal) & $30.33 \pm 6.60$ & $8.33 \pm 5.65$ & 0.0001 \\
\hline DES & $15.66 \pm 17.03$ & $8.45 \pm 7.86$ & NS \\
\hline Hamilton rating scale-D & $10.45 \pm 4.57$ & $1.78 \pm 1.39$ & 0.0001 \\
\hline
\end{tabular}

Note: Soc Ph = social phobia; GAD = generalized anxiety disorder; PD = panic disorder; PdwA = panic disorder with agoraphobia.

History of childhood abuse was assessed with the Early Trauma Inventory - self-report version (ETI; Bremner et al, 2000), a reliable and valid inventory that assesses physical, emotional, and sexual abuse, as well as general traumatic events (Bremner et al, 2000). Subjects were included with a history of childhood physical or sexual abuse, defined as rape, attempted rape, molestation, physical assault or attack with injury, before the age of 18 years. Axis I diagnoses were assessed with the SCID-I disorders (First et al, 1995, see Table 1). Current and lifetime PTSD was assessed with the Clinician-Administered PTSD Scale for DSM-IV (CAPS-DX; Blake et al, 1997), a reliable and valid measure of PTSD symptoms with subcomponents for the individual symptom clusters. PTSD subjects had to fulfill the DSM-IV criteria for PTSD and have a total CAPS score of 50 or higher. Subjects with CAPS scores lower than 50 and who did not fulfill the DSM-IV criteria were included as control subjects. Baseline dissociative traits were assessed by the Dissociative Experience Scale (DES; Bernstein and Putnam, 1986). Depressive mood was assessed using the Hamilton Rating Scale for Depression (HRSD; Hamilton, 1960).

\section{Scripts}

Prior to the challenge day, the subject prepared two personalized scripts with the assistance of an interviewer, using a prior published method (Pitman et al, 1987; Bremner et al, 1999). The participant was first asked to describe a severe childhood sexual or physical abuse event on a script preparation form (trauma script 1). The participant's response was reviewed and a script approximately $1 \mathrm{~min}$ in length was composed by the interviewer portraying the experience in the first person, present tense. Then the participant was asked to describe a second traumatic situation, that is, a situation in which the person felt left alone or abandoned (trauma script 2). Again, a script was composed of about $1 \mathrm{~min}$ in length describing the event in the first person, present tense. As cortisol responses only arise after approximately $20 \mathrm{~min}$ starting from the onset of the stressful situation, the contribution of each individual script on cortisol response cannot be specified. Specific effects of the two scripts on the heart rate, blood pressure, and skin conductance are reported elsewhere (Schmahl et al, submitted).

The subjective impact of the personal trauma scripts was assessed after each script on a 17-item PTSD symptom scale (Southwick et al, 1993); a Clinician-Administered Dissociative States Scale (CADSS, Bremner et al, 1998), a reliable and valid 27-item scale for the measurement of current dissociative states; a Subjective Units of Distress Scale (a visual analog scale ranging from 0 to 100) for the assessment of current subjective levels of distress; and a Visual Analog Scale (ranging from 0 to 100) for the assessment of anxiety.

\section{Memory Tasks}

Paragraph recall. The Wechsler Memory Scale-Revised Logical Memory test (Wechsler, 1987) was used as a valid and sensitive measure of verbal declarative memory that has 
proved to be sensitive to GC effects in previous studies (Newcomer et al, 1994, 1999). The Wechsler memory task is a typical example of declarative memory, using encoding and retrieval strategies. Participants heard two short narratives. Recall for the 25 embedded facts was tested immediately and following a $30 \mathrm{~min}$ intervening period, during which other neuropsychological tests were performed. Two versions (A and B) of the Wechsler memory tests were administered, one after exposure to the trauma scripts, and one 3 days later, which served as a baseline measure. To avoid any nonrandom errors, order of presentation of the two paragraphs was counterbalanced. It was expected that due to enhanced cortisol levels, immediate and delayed recall of the narrative administered immediately after the stress challenge would be impaired compared to the immediate and delayed recall of the narrative presented under resting conditions at day 3 .

To assess memory processing of relevant, emotional material, an emotional paragraph was developed (of a woman alone in her house who got assaulted by her neighbor), also containing 25 embedded facts. To study the effects of stress-induced increases in cortisol levels on encoding and retrieval, this narrative was learned and recalled after exposure to the personalized scripts. To assess the effects of cortisol on long-term consolidation, recall of the story was again assessed 3 days later.

Word recall. Participants received a list of 20 emotional, trauma-related words (eg 'tortured', 'blood'). In a pilot study, these words were rated as more fearful, sad, nervous, angry, and less happy than neutral words (all $P<0.0001$ ). All words had unique word-stems. The investigator (BE) read the words out loud and subjects were instructed to rate how fearful each word was on a 5-point scale. The words were then read a second time, instructing subjects to rate how aversive the word was. To study the effects of cortisol on encoding, word recall was tested 3 days later in a surprise-cued recall task, a word-stem completion task, and a recognition task. It was expected that elevated cortisol levels would be associated with impaired performance on the explicit memory tasks.

For the cued recall task, 10 word-stems were presented corresponding to 10 trauma words instructing the subjects to fill in the word-stems with words that were previously presented. For the word-stem completion task, the 10 remaining target word-stems (not presented in the cued recall task) were presented intermixed with 10 filler wordstems that did not correspond to any previously presented words, to obscure the goal of memory testing. Subjects were instructed to fill in the first word that came to mind. In the recognition task, all 20 target words were presented intermixed with 20 new trauma words. Subjects had to rate how confident they were that they had seen the word before at day 1 using the following rating scale: 1 . I'm sure that the word is new (not studied); 2. Probably new; 3. Probably old; 4. Sure that the word is old (or studied). Subjects were given 2 points each time they assigned a ' 4 ' (sure that the word is old) to a target word, 1 point for each ' 3 ', -1 point for each ' 2 ', and -2 points for each ' 1 '. The total score served as a measure of emotional recognition memory.
Gordon box distractibility task. To control for attention, distractibility was measured using a computer-generated continuous performance task that presented a rapid, continual sequence of numbers in one of three positions, right, center, or left (Gordon Diagnostic System (GDS); Gordon and Mettelman, 1987). In a first presentation, participants had to press a key every time they saw a ' 9 '. In a second presentation, participants were required to respond by pressing a key to each ' 9 ' that appeared immediately after a ' 1 ', but only if they both appeared sequentially in the center position. The total number of correct responses and reaction latencies were analyzed.

\section{Cortisol}

Cortisol levels were monitored using saliva sampling to prevent the stress-inducing effects of blood sampling. Determination of cortisol in saliva provides a reliable measure of the free unbound fraction of cortisol (Tunn et al, 1992). Saliva samples were collected at 14 time-points before, during, and after the trauma scripts exposure. Preexposure levels of cortisol were assessed at 20,10,5, and $0 \mathrm{~min}$ before exposure to the scripts; cortisol levels during trauma exposure were assessed at 5, 10, 15, and 20 min after exposure to the first trauma script, and cortisol levels during recovery were assessed at $25,30,40,50,60$, and $75 \mathrm{~min}$ after exposure to the first trauma script (see Figure 1). Saliva samples were collected using Salivette collection devices and stored at $-70^{\circ} \mathrm{C}$. Salivette tubes were centrifuged $\left(0-4^{\circ} \mathrm{C}\right)$ to prepare saliva, which was analyzed for cortisol using a 125I immunoradiometric assay kit available from Diagnostic Products Corporation (Los Angeles, CA). Samples and standards $(200 \mu \mathrm{l})$ were determined in duplicate. Day-to-day coefficients for low (389 pg/ $\mathrm{ml})$ and high $(4.12 \mathrm{ng} / \mathrm{ml})$ concentration quality assessment (QC) samples were 10.1 and $8.4 \%$, respectively.

\section{Procedure}

The study was conducted in the afternoon (between 1400 and 1700 hoursp.m.) in order to have a standard time-point relative to normal diurnal cortisol variations. Participants

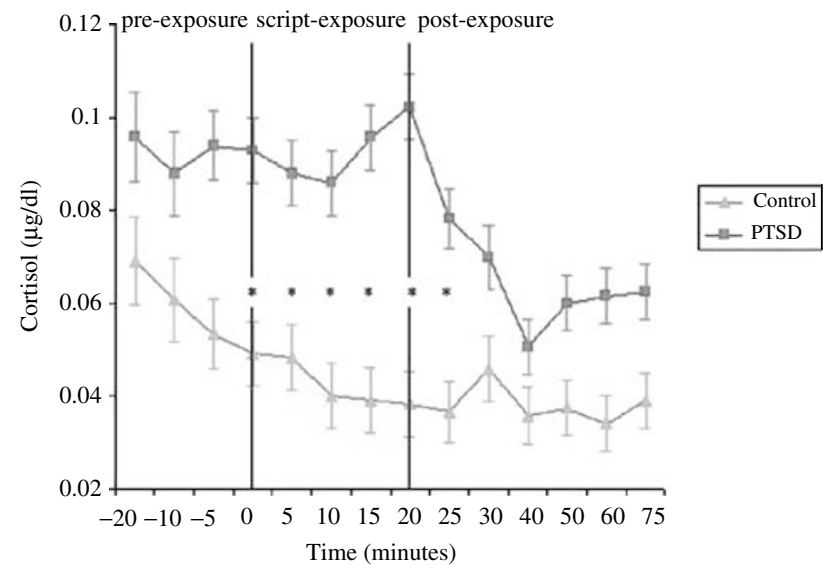

Figure I Cortisol levels $(\mu \mathrm{g} / \mathrm{dl})$ and standard error of means (SEMs) before, during, and after trauma script exposure for women with and without PTSD. Women with PTSD had elevated levels of cortisol during and shortly after the script exposure compared to controls (t0-t25). 
had to refrain from strenuous physical exercise, large meals, cigarette smoking, and coffee for at least $1 \mathrm{~h}$ prior to the experiment, because of the known effects of these variables on cortisol secretion. Subjects were placed in a quiet room in a reclining chair. After a resting period of $20 \mathrm{~min}$, a standardized neutral story $1 \mathrm{~min}$ in length was read by a female investigator. Subjects were then asked to imagine the story for $2 \mathrm{~min}$. After the imagination period, subjective ratings of PTSD symptoms, dissociation, anxiety, and general distress were collected. After $30 \mathrm{~min}$, the first personal trauma script was read out loud, followed by an imagination period of $2 \mathrm{~min}$ in which subjects were asked to imagine the script as vividly as possible. After this, the subjective ratings were assessed. This procedure was repeated after $10 \mathrm{~min}$ with the presentation of the second trauma script. The order of the two scripts was randomized. After exposure to the trauma scripts, subjects had a resting period of $5 \mathrm{~min}$ after which the memory assessment took place in the same fixed order: Wechsler paragraph (A) immediate recall; rating of emotional words; learning and immediate recall of the emotional story; Wechsler paragraph (A) delayed recall; and two distractibility tasks. The complete procedure took about $1.5 \mathrm{~h}$.

At 3 days after the script exposure, subjects came back for a 30-min memory assessment. In a same fixed order, the following memory tests were administered: Wechsler paragraph (B) immediate recall (baseline); word-stem completion, cued recall and recognition task of the emotional words; delayed paragraph recall of emotional story; and Wechsler paragraph (B) delayed recall (baseline).

\section{STATISTICS}

Cortisol levels during the experiment were calculated using repeated measures design with the 14 separate time-points as the within-subject factor and the PTSD $v s$ control group as the between-subject factor. Differences in cortisol levels at separate time-points between the two groups were calculated using $t$-tests for independent samples (twotailed). Memory performance between the two groups was calculated using $t$-tests for paired samples (two-tailed). Paragraph recall before and after stress exposure was analyzed using a 2 (immediate $v s$ delayed recall) by 2 (stress $v s$ baseline) repeated measures design followed by post hoc $t$-tests. Subjective measures were calculated using a repeated measures design with the two diagnostic groups as the between-subject factor and the three scripts (neutral, trauma script 1, and trauma script 2) as the within-subject factor, followed by post hoc t-tests. Correlations between cortisol levels and CAPS scores, and between cortisol levels and memory performance were calculated using Pearson's correlations.

\section{RESULTS}

\section{Cortisol Levels in Response to Trauma Scripts}

Abused women with PTSD demonstrated higher cortisol levels compared to controls (main effect for diagnosis: $\mathrm{F}[1,22]=4.08, P=0.056$, Figure 1). Cortisol levels were elevated by an average of $122 \%$ in PTSD patients compared to controls during script exposure (mean of time-points 5,
$10,15$, and $20 \mathrm{~min} ; t(22)=2.82, P<0.01), v s 60 \%$ during the pre-exposure period (mean of time-points $-20,-10,-5$, and $0 \mathrm{~min} ; t(22)=1.51$, NS), and $69 \%$ during the postexposure period (mean of time-points $25,30,40,50,60$, and 75 min: $t(22)=1.66$, NS). Comparisons at separate timepoints revealed that women with PTSD had significantly higher cortisol levels than controls during and shortly after the script exposure (time-points $t 0-t 25): t_{t 0}(22)=2.17$, $P<0.05 ; \quad t_{t 5}(22)=2.19, \quad P<0.05 ; \quad t_{t 10}(22)=2.28, \quad P<0.05$; $t_{t 15}(22)=2.83, \quad P<0.01 ; \quad t_{t 20}(22)=3.19, \quad P<0.01 ; \quad$ and $t_{t 25}(22)=2.23, \quad P<0.05$, all two-tailed (see asterixes in Figure 1).

For the group as a whole, cortisol levels were lower during the postexposure period (from 25 min onwards) than before and during script exposure (ie significant main effect for time: $F[13,299]=6.00, P<0.001)$. This main effect of time was specified by a significant group by time interaction $(\mathrm{F}[13,286]=1.95, \quad P<0.05)$ : Abused women with PTSD exhibited a strong decrease in cortisol after the script exposure, whereas controls did not.

To examine the effect of depression on cortisol levels, PTSD patients with $(n=3)$ and without $(n=9)$ a comorbid depression were compared. No differences were detected (mean cortisol of women without depression $=0.082 \pm 0.052 \mu \mathrm{g} / \mathrm{dl} v s$ mean cortisol of women with depression $=0.075 \pm 0.014 \mu \mathrm{g} / \mathrm{dl})$. To assess the effects of medication on cortisol levels, mean cortisol levels of medicated subjects with $(n=4)$ and without PTSD $(n=5)$ were compared to cortisol levels of unmedicated subjects with $(n=8)$ and without PTSD $(n=7)$. In both groups, mean cortisol levels were somewhat lower in medicated subjects $(\mathrm{PTSD}=0.071 \pm 0.008 \mu \mathrm{g} / \mathrm{dl}$ and controls $=0.016 \pm$ $0.004 \mu \mathrm{g} / \mathrm{dl}$ ) relative to unmediated subjects (PTSD $=$ $0.086 \pm 0.056 \mu \mathrm{g} / \mathrm{dl}$ and controls $=0.065 \pm 0.043 \mu \mathrm{g} / \mathrm{dl}$ ). This effect appeared to be stronger in the control group, but sample sizes were too small to allow statistical analyses.

\section{Correlations Between Cortisol and PTSD Symptomatology}

Correlations between cortisol levels and severity of PTSD symptoms as assessed with the Clinician-Administered PTSD Scale (CAPS) during the diagnostic assessment (indicating the severity of post-traumatic symptoms during the past 2 weeks) were high during and shortly after exposure to the trauma scripts, but moderate under resting conditions (both pre- and postexposure) (see Figure 2, correlations higher than \pm 0.40 are significant at the 0.05 level). Re-experiencing symptoms (subscale B) and arousal symptoms (subscale D) were especially correlated with cortisol release, whereas avoidance behavior (subscale C) yielded lower correlations.

\section{Subjective Measures}

Abused women with PTSD reported more PTSD symptoms, dissociative symptoms, and anxiety to the trauma scripts than abused women without PTSD (Table 2). For the sample as a whole, exposure to the trauma scripts resulted in elevated PTSD symptoms $(\mathrm{F}[2,44]=36.41, P<0.001)$, dissociative symptoms $(\mathrm{F}[2,44]=7.64, \quad P<0.001)$, anxiety 


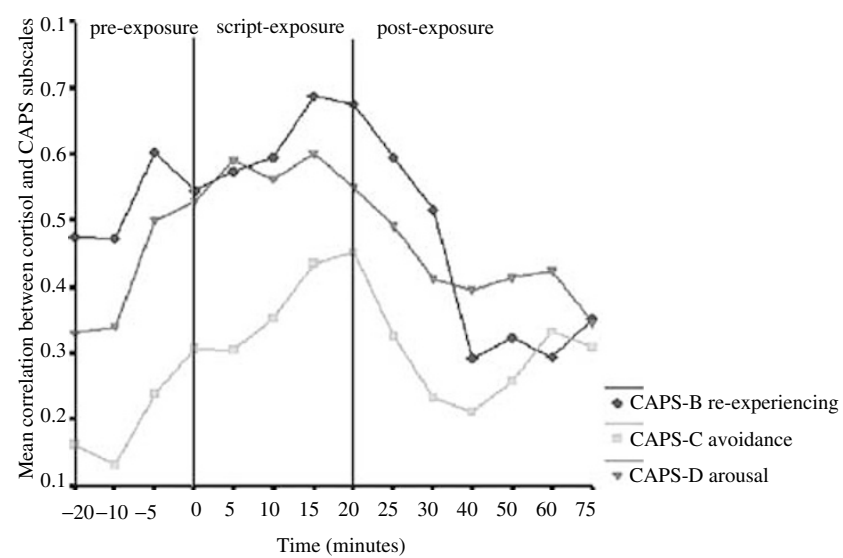

Figure 2 Mean Pearson's correlations between cortisol levels at the separate time-points during the study and baseline PTSD symptomatology as measured with the CAPS during diagnostic assessment. Note: Correlations higher than \pm 0.40 are significant at the 0.05 level.

$(\mathrm{F}[2,44]=11.76, \quad P<0.001), \quad$ and subjective distress $(\mathrm{F}[2,44]=24.38, P<0.001)$ compared to the neutral script. No interaction was found between the script and group.

\section{Memory}

Compared to the abused women without current PTSD, abused women with PTSD tended to recall less emotional words 3 days after the challenge day, and recognized new words less well than words not previously studied (see Table 3). With Bonferroni correction, these differences were no longer significant. No differences were found between the two groups on (neutral or emotional) paragraph recall at the day of the challenge or at baseline.

In a repeated-measures ANOVA on the immediate $v s$ delayed recall of the (neutral) paragraphs after exposure $v s$ baseline, the average recall after the trauma script exposure was impaired relative to the average recall during baseline $(\mathrm{F}[1,21]=49.41, P<0.001)$. The expected main effect of time was also found $(\mathrm{F}[1,21]=6.81, P<0.05)$, indicating that delayed paragraph recall was decreased compared to immediate recall. Interestingly, these main effects were specified by a significant interaction between time and testing condition $(\mathrm{F}[1,21]=8.41, P<0.01)$. A post hoc analysis revealed that delayed recall was particularly decreased after the script exposure (delayed paragraph recall after stress exposure $=12.46 \pm 3.84$ units $v s$ delayed paragraph recall during baseline $=16.57 \pm 4.30$ units, $t(22)=-3.39, P<0.01)$, whereas immediate recall was not (immediate recall after stress exposure $=15.20 \pm 4.05$ units $v s$ immediate recall during baseline $=17.18 \pm 4.20$ units, $t(22)=-1.53$, NS)

\section{Correlations with Cortisol}

A positive correlation was found between cortisol levels during encoding (t30) and recall of the emotional paragraph at day $3(r=0.48, P<0.05)$. No other significant correlations were found between cortisol levels and recall of the neutral or emotional paragraphs at day 3 or with any other measure of memory function immediately after the stress exposure.

\section{DISCUSSION}

Women with PTSD demonstrated significantly elevated cortisol levels compared to abused women without PTSD when exposed to personalized scripts of childhood abuse, with the greatest magnitude of elevations during and shortly after exposure to the trauma scripts. During recovery, cortisol levels in the PTSD group dropped significantly to a level similar to the non-PTSD group. Taken together, these findings are consistent with findings of increased negative feedback sensitivity (Yehuda et al, 1993; Stein et al, 1997). In conjunction with prior studies showing decreased or normal cortisol levels at baseline, these findings may suggest increased cortisol levels following exposure to stress with suppressed baseline activation.

During and shortly after exposure to the trauma scripts, cortisol levels were strongly associated with PTSD symptoms as assessed with the CAPS. Thus, the severity of PTSD symptoms experienced during the 2 weeks prior to the study was highly predictive of cortisol levels with exposure to the trauma scripts. This was particularly true for reexperiencing and arousal symptoms, and less so for avoidance (that measures behavior rather than an internal state'). It was striking that both before and after exposure to

Table 2 Mean ( \pm SD) Psychological Ratings for Women with and without PTSD After Listening to a Neutral Script, and the Two Trauma Scripts Describing Their Childhood Abuse

\begin{tabular}{|c|c|c|c|c|c|}
\hline PTSD $(n=12)$ & $\begin{array}{c}\text { Neutral Script } \\
\text { Mean } \pm \text { SD }\end{array}$ & $\begin{array}{c}\text { Trauma Script I } \\
\text { Mean } \pm \text { SD }\end{array}$ & $\begin{array}{c}\text { Trauma Script } 2 \\
\text { Mean } \pm \text { SD }\end{array}$ & $\mathbf{F}$ & $P$-value two-tailed \\
\hline PTSD symptoms & $21.67 \pm 11.92$ & $37.25 \pm 15.06^{*}$ & $32.83 \pm 15.30 *$ & 28.49 & $0.000^{t 1>t 2>n}$ \\
\hline CADSS & $6.25 \pm 9.37 *$ & $13.00 \pm 18.42 *$ & $9.75 \pm 13.90 *$ & 5.88 & $0.090^{t 1>t 2>n}$ \\
\hline Anxiety & $1.17 \pm 1.03$ & $2.17 \pm 1.03^{*}$ & $1.75 \pm 1.22 *$ & 20.32 & $0.000^{t 1>t 2>n}$ \\
\hline SUDS & $22.25 \pm 22.94$ & $46.67 \pm 25.44$ & $40.83 \pm 26.36$ & 27.33 & $0.000^{t 1+t 2>n}$ \\
\hline \multicolumn{6}{|l|}{ Controls $(n=12)$} \\
\hline PTSD symptoms & $16.17 \pm 4.39$ & $27.58 \pm 10.22 *$ & $24.42 \pm 5.79 *$ & 11.35 & $0.000^{t 1+t 2>n}$ \\
\hline CADSS & $0.67 \pm 0.98 *$ & $2.92 \pm 4.94 *$ & $1.33 \pm 1.83 *$ & 1.86 & $0.180^{t 1}=t 2=n$ \\
\hline Anxiety & $0.58 \pm 0.67$ & $0.83 \pm 0.94 *$ & $0.75 \pm 0.87 *$ & 0.76 & $0.480^{t 1}=t 2=n$ \\
\hline SUDS & $20.83 \pm 17.30$ & $36.25 \pm 25.60$ & $35.17 \pm 22.10$ & 5.86 & $0.009^{t 1+t 2>n}$ \\
\hline
\end{tabular}

Note: CADSS: Clinician-Administered Dissociative States Scale; SUDS: Subjective Units of Distress Scale; *Significant main effect for diagnosis (P<0.05, one-sided). $t \mid=$ trauma script $1 ; t 2=$ trauma script $2 ; n=$ neutral script. 
Table 3 Memory Data of Women with and without PTSD

\begin{tabular}{|c|c|c|c|}
\hline Memory tasks & $\begin{array}{c}\text { PTSD }(n=12) \\
\text { Mean } \pm \text { SD }\end{array}$ & $\begin{array}{c}\text { Controls }(n=12) \\
\text { Mean } \pm \text { SD }\end{array}$ & $P$-value two-tailed \\
\hline \multicolumn{4}{|c|}{ Neutral paragraph recall A (stress cond.) } \\
\hline Immediate recall (day I) & $|4.7| \pm 4.05$ & $16.04 \pm 4.12$ & NS \\
\hline Delayed recall (day I) & $12.58 \pm 4.66$ & $12.92 \pm 3.46$ & NS \\
\hline Percentage recall & $84.4 \pm 20.27 \%$ & $81.2 \pm 13.19 \%$ & NS \\
\hline \multicolumn{4}{|c|}{ Neutral paragraph recall B (baseline) } \\
\hline Immediate recall (day 3) & $18.05 \pm 4.10$ & $16.38 \pm 4.30$ & NS \\
\hline Delayed recall (day 3) & $17.23 \pm 4.51$ & $15.96 \pm 4.21$ & NS \\
\hline Percentage recall & $95.0 \pm 8.75 \%$ & $98.4 \% \pm 11.61$ & NS \\
\hline \multicolumn{4}{|l|}{ Emotional paragraph recall } \\
\hline Immediate recall (day I) & $\mid 4.83 \pm 4.39$ & $15.17 \pm 3.07$ & NS \\
\hline Delayed recall (day 3) & $6.80 \pm 4.75$ & $7.00 \pm 4.53$ & NS \\
\hline Percentage recall & $49.9 \pm 29.02 \%$ & $44.5 \pm 23.87 \%$ & NS \\
\hline \multicolumn{4}{|l|}{ Emotional word recall (day 3) } \\
\hline Cued recall & $0.85 \pm 0.97$ & $1.88 \pm 1.52$ & 0.07 \\
\hline Implicit memory & $00.46 \pm 0.64$ & $0.54 \pm 0.66$ & NS \\
\hline Recognition (old) & $|4.72 \pm 7.3|$ & $21.36 \pm 6.77$ & NS \\
\hline Recognition (new) & $1.00 \pm 6.62$ & $8.18 \pm 7.28$ & 0.03 \\
\hline \multicolumn{4}{|l|}{ Distractibility task (day I) } \\
\hline No. of correct answers & $29.08 \pm 1.83$ & $28.91 \pm 1.81$ & NS \\
\hline Reaction time & $49.67 \pm 10.85$ & $48.45 \pm 20.84$ & NS \\
\hline
\end{tabular}

Note: Percentage recall $=($ delayed recall/immediate recall $) \times 100$.

the trauma scripts, correlations between cortisol and CAPS scales dropped to nonsignificant levels, indicating that PTSD symptoms are not a good predictor of cortisol levels under resting conditions.

This pattern of results may provide new insights into the mixed findings on baseline HPA-axis functioning in PTSD, with several studies reporting lowered (Mason et al, 1986; Yehuda et al, 1990, 1996), and others reporting elevated levels of cortisol measured in 24-h urine in patients with PTSD (Pitman and Orr, 1990; Lemieux and Coe, 1995; De Bellis et al, 1999). Rather than a consistent pattern of static 'hypocortisolism' or 'hypercortisolism', (internal or external) confrontations with traumatic reminders or other stressful conditions may determine levels of cortisol, with decreases in cortisol levels being related to suppression of cortisol function to compensate for periods of increased cortisol levels during stress. This is supported by the finding of marked lability of urinary free cortisol levels at admission, midcourse, and discharge during a 90-day hospitalization period in male Vietnam combat veterans with PTSD (Mason et al, 2002).

Women with PTSD, and control subjects to a lesser extent, had higher cortisol levels before being exposed to the trauma scripts than during the period following the scripts exposure. This probably reflects heightened HPA activity due to anticipatory anxiety, as the women were informed about the procedure, and all were anxious in anticipation of it. Previous studies have demonstrated that anticipation of a stressful event may be a potent activator of HPA activity, with HPA activation often starting even before an acute stressor is applied (Kirschbaum et al, 1993; Richter et al, 1996). Moreover, elevated levels of cortisol were also found in PTSD patients in anticipation of a cognitive stress challenge (Bremner et al, 2003b). Owing to this lack of a proper baseline, it could not be determined with certainty whether cortisol levels had increased in PTSD patients in response to the trauma scripts (starting already prior to the experiment). The significant drop in cortisol levels during the recovery phase may suggest that this was the case. Moreover, a large part of the present sample took part in a study on the assessment of the HPA-axis over a 24-h diurnal period and in response to neuroendocrine challenges, in which lower levels of cortisol were found for the PTSD women during the afternoon hours (12-8 pm) compared to non-PTSD women (see Bremner et al, 2003a). Clearly, future studies on stress responsivity of the HPA-axis in PTSD should also assess proper baseline cortisol levels, measured on a separate day than the challenge.

In both PTSD patients and controls, memory consolidation was impaired following stress exposure compared to baseline measurements. However, this appeared to be independent of cortisol levels. With Bonferroni correction, no differences were found between the two groups in the recall of emotional or neutral words or paragraphs. Moreover, we did not find any of the expected negative correlations between cortisol and memory performance. One explanation for this may be related to the fact that exposure to the trauma scripts caused rather moderate elevations in cortisol levels. The peak levels of cortisol were (far) below cortisol levels associated with memory impairments in healthy subjects who have been exposed to a psychosocial stress challenge (Kirschbaum et al, 1996; Elzinga et al, submitted) or to synthetic cortisol (Lupien et al, 1999; Kirschbaum et al, 1996). Apparently, stressors with the duration and the intensity of the trauma scripts do not induce cortisol levels high enough to reduce memory 
functioning. It cannot be dismissed, however, that more elevated cortisol levels, elicited by exposure to more intense or aversive stressors (eg chronic stressors or highly emotional or traumatic events such as sexual or physical abuse) may be associated with decreases in memory functioning.

The only significant correlation that did arise was a positive relation between cortisol levels and recall of the emotional story, so that the higher the cortisol, the better the story was recalled. The positive correlation was inconsistent with our hypothesis based on prior studies (Newcomer et al, 1994, 1999; Kirschbaum et al, 1996). However, these studies included only neutral material. Based on animal studies, it might be hypothesized that cortisol has a differential effect on neutral $v s$ emotional memory performance. Emotional arousal may enhance memory functioning due to a complex interaction between corticosteroids and adrenergic activity in the basolateral nucleus of the amygdala (McGaugh, 2000; Roozendaal, 2000). This was supported by a recent study in healthy subjects reporting enhancing effects of cortisol on the recall of emotional pictures (Buchanan and Lovallo, 2001). Clearly, more studies with various levels of both stressinduced and pharmacologically administered cortisol need to be conducted to gain more insight into the association between various cortisol levels, norepinephrine, and memory functioning related to neutral and emotional events.

Several limitations should be considered in evaluating our findings. First, the sample size was rather small with 12 women with and 12 women without current PTSD. Second, about a third of the subjects, equally distributed among the two groups, was taking psychotropic medication during the investigation. As evidence is accumulating that antidepressants may reduce reactivity of the HPA-axis, more studies are needed that investigate the effects of cortisol reactivity in nonmedicated $v s$ medicated PTSD patients and control subjects. Moreover, all subjects, including the control subjects, had a lifetime diagnosis of PTSD. It is still unknown whether the cortisol responses of traumatized women with a history of PTSD can be generalized to individuals with a history of childhood abuse who have never developed PTSD. This would be another interesting question for future study. Furthermore, no subjects were included who had no history of sexual or physical abuse and no PTSD. It cannot be dismissed that nonabused healthy individuals may show even higher cortisol levels in response to similar stressors compared to the two abused samples. Instead of PTSD patients showing elevated cortisol levels following exposure to traumatic reminders, this would rather be indicative of a relative hyposecretion of cortisol in abused individuals without current PTSD. For a definite answer to this interesting issue, a direct comparison among these three groups would be necessary. Obviously, in such a study, participants would have to be exposed to a more general type of stressor, as a nonabused group can by definition not generate a personal trauma script as was used in the present study. Another limitation is that only cortisol levels were assessed in this study. To study HPA regulation in more detail, the separate components of the stress axis need to be measured, including ACTH. Moreover, the HPAaxis and the locus coeruleus/noradrenergic system have mutual interconnections. PTSD may be associated with dysfunctional connectivity between those systems. It would be informative, therefore, to assess these different stress systems within one study.

A question that arises from this study is whether the pattern of elevated cortisol levels in patients with PTSD when confronted with traumatic reminders will be reduced after successful treatment. As all women in the control group had a lifetime diagnosis of PTSD, this might suggest that this is indeed the case. To study this issue more directly, cortisol responses to trauma scripts both before and after either pharmacological or psychological treatment should be assessed.

\section{ACKNOWLEDGEMENTS}

We thank Helen Sayward, MS, Kathy West, BS, and Monica Lee-Carter for assistance in conducting these studies. This study was supported by a grant from the Foundation for Behavioral and Educational Sciences of the Netherlands Organization of Scientific Research (NWO) awarded to Prof Dr van Dyck (\#575-29-003) and by NIMH R01 MH56120, VA Career Development Award, and the National Center for PTSD Grant awarded to Dr Bremner.

\section{REFERENCES}

Anisman H, Zaharia MD, Meaney MJ, Merali Z (1998). Do earlylife events permanently alter behavioral and hormonal responses to stressors?. Intern J Dev Neurosci 16: 149-164.

Arbel I, Kadar T, Silberman M, Levy A (1994). The effects of longterm corticosterone administration on hippocampal morphology and cognitive performance of middle-aged rats. Brain Res 657: 227-235.

Beitchman JH, Zucker KJ, Hood JE, daCosta GA, Akman D, Cassavia E (1992). A review of the long-term effects of child sexual abuse. 1. Child Abuse Negl 16: 101-118.

Bernstein E, Putnam F (1986). Development, reliability, and validity of a dissociation scale. J Nerv Ment Dis 174: 727-735.

Blake DD, Weathers FW, Nagy LM, Kaloupek DG, Charney DS, Keane TM (1997). Clinician-Administered PTSD Scale for DSMIV, Current and Lifetime Version. National Center for Posttraumatic Stress Disorder: Boston, West Haven.

Bremner JD (1999). Does stress damage the brain? Biol Psychiatry 45: 797-805.

Bremner JD, Krystal JH, Putnam FW, Southwick SM, Marmer C, Charney DS et al (1998). Measurement of dissociative states with the clinician administered dissociative states scale (CADSS). $J$ Traum Stress 11: 125-136.

Bremner JD, Licinio J, Darnell A, Krystal JH, Owens MJ, Southwick SM et al (1997). Elevated CSF corticotropin-releasing factor concentrations in posttraumatic stress disorder. Am J Psychiatry 154: 624-629.

Bremner JD, Southwick SM, Charney DS (1999). The neurobiology of posttraumatic stress disorder: an integration of animal and human research. In: Saigh PA, Bremner JD (eds). Posttraumatic Stress Disorder: A Comprehensive Text. Allyn and Bacon: Boston. pp 103-143.

Bremner JD, Southwick SM, Johnson DR, Yehuda R, Charney DS (1993). Childhood physical abuse and combat-related posttraumatic stress disorder. Am J Psychiatry 150: 234-239.

Bremner JD, Vermetten E, Mazure CM (2000). Development and preliminary psychometric properties of an instrument for the measurement of childhood trauma: the early trauma inventory. Depress Anxiety 12: 1-12. 
Bremner JD, Vythilingam M, Anderson G, Vermetten E, McGlashan T, Heninger $G$ et al (2003a). Assessment of the hypothalamic-pituitary-adrenal (HPA) axis over a 24-hour diurnal period and in response to neuroendocrine challenges in women with and without early childhood sexual abuse and posttraumatic stress disorder (PTSD). Biol Psychiatry, in press.

Bremner JD, Vythilingam M, Vermetten E, Adil J, Khan S, Nazeer A et al (2003b). Cortisol response to a cognitive stress challenge in posttraumatic stress disorder (PTSD) related to childhood abuse. Psychoneuroendocrinology, in press.

Brown GR, Anderson B (1991). Psychiatric morbidity in adult inpatients with histories of sexual and physical abuse. Am J Psychiatry 148: 55-61.

Buchanan TW, Lovallo WR (2001). Enhanced memory for emotional material following stress-level cortisol treatment in humans. Psychoneuroendocrinology 26: 307-317.

Conrad CD, Galea LA, Kuroda Y, McEwen BS (1996). Chronic stress impairs rat spatial memory on the Y maze, and this effect is blocked by tianeptine pretreatment. Behav Neurosci 110: 1321-1334.

De Bellis MD, Baum AS, Birmaher B, Keshaven MS, Eccard CH, Boring AM et al (1999). Developmental traumatology, Part I: biological stress systems. Biol Psychiatry 45: 1259-1267.

Draijer N, Langeland W (1999). Childhood trauma and perceived parental dysfunction in the etiology of dissociative symptoms in psychiatric inpatients. Am J Psychiatry 156: 379-385.

Elzinga BM, Bakker A, Bremner JD (submitted). The effects of stress-induced cortisol release on memory consolidation.

Elzinga BM, Bremner JD (2002). Are the neural substrates of memory the final common pathway to PTSD? J Affective Dis 70: $1-17$.

First MB, Spitzer RL, Williams JBW, Gibin M (1995). Structural Clinical Interview for DSM-IV-Patients Edition (SCID-P). American Psychiatric Press: Washington, DC.

Golier J, Yehuda R (1998). Neuroendocrine activity and memoryrelated impairments in posttraumatic stress disorder. Dev Psychopathol 10: 857-869.

Gordon M, Mettelman BB (1987). Technical Guide to the Gordon Diagnostic System. Gordon Systems, Inc.: Syracuse.

Hamilton M (1960). A rating scale for depression. J Neurol Neurosurg Psychiatry 23: 56-62.

Heim C, Newport DJ, Heit S, Graham YP, Wilcox M, Bonsall R et al (2000). Pituary-adrenal and autonomic responses to stress in women after sexual and physical abuse in childhood. JAMA 284: 592-597.

Howard J, Olney J, Frawley J (1955). Studies of adrenal function in combat and wounded soldiers. Ann Surg 141: 314-317.

Kanter ED, Wilkinson CW, Radant AD, Petrie EC, Dobie DJ, McFall ME et al (2001). Glucocorticoid feedback sensitivity and adrenocortical responsiveness in posttraumatic stress disorder. Biol Psychiatry 50: 238-245.

Keenan PA, Jacobson MW, Soleyman RM, Newcomer JW (1995). Commonly used therapeutic doses of glucocorticoids impair explicit memory. Ann NY Acad Sci 761: 400-402.

Kessler RC, Sonnega A, Bromet E, Hughes M, Nelson CB (1995). Posttraumatic stress disorder in the national comorbidity survey. Arch Gen Psychiatry 52: 1048-1060.

Kirschbaum C, Pirke KM, Helhammer DH (1993). The Trier social stress test' - a tool for investigating psychobiological stress responses in a laboratory setting. Neuropsychobiology 28: 76-81.

Kirschbaum C, Wolf OT, May M, Wippich W, Hellhammer DH (1996). Stress- and treatment-induced elevations of cortisol levels associated with impaired declarative memory in healthy adults. Life Sci 58: 1475-1483.

Lemieux A, Coe C (1995). Abuse-related posttraumatic stress disorder: evidence for chronic neuroendocrine activation in women. Psychosom Med 57: 105-112.
Liberzon I, Abelson JL, Flagel SB, Raz J, Young EA (1999). Neuroendocrine and psychophysiologic responses in PTSD: a symptom provocation study. Neuropsychopharmacology 21: 40-50.

Luine V, Villages M, Martinez C, McEwen BS (1994). Repeated stress causes reversible impairments of spatial memory performance. Brain Res 639: 167-170.

Lupien SJ, Gaudreau S, Tchiteya BM, Maheu FS, Sharma S, Nair NPV et al (1997). Stress-induced declarative memory impairment in healthy elderly subjects: relationship to cortisol reactivity. J Clin Endocrinol Metab 82: 2070-2075.

Lupien SJ, Gillin CJ, Hauger R (1999). Working memory is more sensitive than declarative memory to the acute effects of corticosteroids: a dose-response study in humans. Behav Neurosci 113: 420-430.

Mason JU, Giller E, Kosten T, Ostroff R, Podd L (1986). Urinary free cortisol levels in PTSD-patients. J Nerv Ment Dis 174: $145-155$.

Mason JU, Wang S, Yehuda R, Lubin H, Johnson D, Bremner JD et al (2002). Marked lability in urinary cortisol levels in subgroups of combat veterans with posttraumatic stress disorder during an intensive exposure treatment program. Psychosom Med 64: 238-246.

McCauley J, Kern D, Koloder K, Dill L, Schroeder AF, DeChant HK et al (1997). Clinical characteristics with a history of childhood abuse. JAMA 277: 1362-1368.

McEwen BS (2000). The neurobiology of stress: from serendipity to clinical relevance. Brain Res 886: 172-189.

McEwen BS, Angulo J, Cameron H, Chao HM, Daniels D, Gannon MN et al (1992). Paradoxical effects of adrenal steroids on the brain: protection versus degeneration. Biol Psychiatry 31: 177-199.

McGaugh JL (2000). Memory - a century of consolidation. Science 287: 248-251.

Newcomer JW, Craft S, Hershey T, Askins K, Bardgett ME (1994). Glucocorticoid-induced impairment in declarative memory performance in adult humans. J Neurosci 14: 2047-2053.

Newcomer JW, Selke G, Melson AK, Hershey T, Craft S, Richards K et al (1999). Decreased memory performance in healthy humans induced by stress level cortisol treatment. Arch Gen Psychiatry 56: $527-533$.

Ohl F, Michaelis T, Vollmann-Honsdorf GK, Kirschbaum C, Fuchs E (2000). Effect of chronic psychosocial stress and long-term cortisol treatment on hippocampus-mediated memory and hippocampal volume; a pilot-study in tree shrews. Psychoneuroendocrinology 25: 357-363.

Orr SP, Pitman RK, Lasko NB, Herz LR (1993). Posttraumatic stress disorder imagery in World War II and Korean combat veterans. J Abnorm Psychol 102: 152-159.

Pitman R, Orr S (1990). Twenty-four hour urinary cortisol and cathecholamine excretion in combat-related PTSD. Biol Psychiatry 27: 245-249.

Pitman RK, Orr SP, Forgue DF, Altman B, de Jong JB, Herz LR (1990). Psychophysiological responses to combat imagery of Vietnam veterans with post-traumatic stress disorder vs other anxiety disorders. J Abnorm Psychol 99: 49-54.

Pitman RK, Orr SP, Forgue DF, de Jong JB, Claiborn JM (1987). Psychophysiologic assessment of posttraumatic stress disorder imagery in Vietnam combat veterans. Arch Gen Psychiatry 44: 970-975.

Plotsky PM, Meany MJ (1993). Early, postnatal experiences alters hypothalamic corticotropin-releasing factor (CRF) mRNA, median eminence CRF content and stress-induced release in adult rats. Mol Brain Res 18: 195-200.

Resnick HS, Yehuda R, Pitman RK, Foy DW (1995). Effect of previous trauma on acute plasma cortisol level following rape. American Journal of Psychiatry 152: 1675-1677. 
Richter SD, Schurmeyer TH, Schedlowksi M, Hadicke A, Tewes U, Schmidt RE et al (1996). Time kinetics of the endocrine response to acute psychological stress. J Clin Endocrinol Metab 81: 1956-1960.

Roozednaal B (2000). Glucocorticoids and the regulation of memory consolidation. Psychoneuroendocrinology 25: 213-238.

Sapolsky RM (1996). Why stress is bad for your brain. Science 273: 749-750.

Sapolsky RM (1997). The importance of a well-groomed child. Science 12: 1659-1662.

Shalev AY, Orr SP, Pitman RK (1993). Psychophysiological assessment of traumatic imagery in Israeli civilian posttraumatic stress disorder. Am J Psychiatry 150: 620-624.

Southwick SM, Krystal JH, Morgan CA, Johnson D, Nagy LM, Nicolaou A et al (1993). Abnormal noradrenergic function in posttraumatic stress disorder. Arch Gen Psychiatry 50: 266-274.

Squire LR, Zola-Morgan S (1991). The medial temporal lobe memory system. Science 253: 1380-1386.

Stein M, Yehuda R, Koverola C, Hanna C (1997). Enhanced dexamethasone suppression of plasma cortisol in adult women traumatized by childhood sexual abuse. Biol Psychiatry 42: 680-690.

Tunn S, Mollmann H, Barth J, Derendorf H, Krieg M. (1992). Simultaneous measurement of cortisol in serum and saliva after different forms of cortisol administration. Clinical Chemistry 38: 1491-1494.

Wechsler D (1987). Wechsler Memory Scale-Revised. Harcourt Brace Jovanovich, Inc.: New York, NY.
Wolkowitz OM, Reus VI, Weingartner H, Thompson K, Breier A, Doran A et al (1990). Cognitive effects of corticosteroids. Am J Psychiatry 147: 1297-1303.

Yehuda R, Boiseneau D, Lowy M, Giller E (1995a). Dose-response changes in plasma cortisol and lymphocyte glucocorticoid receptors following dexamethasone administration in combat veterans with and without posttraumatic stress disorder. Arch Gen Psychiatry 52: 583-588.

Yehuda R, Kahana B, Binder-Brynes K, Southwick S, Mason J, Giller E (1995b). Low urinary cortisol excretion in holocaust survivors with posttraumatic stress disorder. Am J Psychiatry 152: 982-990.

Yehuda R, Teicher MH, Trestman RL, Levengood RA, Siever LJ (1996). Cortisol regulation in posttraumatic stress disorder and major depression: A chronobiological analysis. Biological Psychiatry 40: 79-88.

Yehuda R, Resnick H, Schmeidler J, Yang R, Pitman R (1998). Predictors of cortisol and 3-methoxy-4-hydroxy-phenylglycol responses in the acute aftermath of rape. Biol Psychiatry 43: 855-862.

Yehuda R, Southwick S, Krystal J, Bremner JD, Charney D, Mason J (1993). Enhanced suppression of cortisol with low-dose dexamethasone in PTSD. Am J Psychiatry 150: 83-87.

Yehuda R, Southwick S, Nussbaum G, Wahby V, Giller EL, Mason JW (1990). Enhanced low urinary cortisol secretion in patients with posttraumatic stress disorder. J Nerv Ment Dis 178: $366-369$. 